\title{
THE NEHARI MANIFOLD FOR A $p$-LAPLACIAN EQUATION WITH CONCAVE-CONVEX NONLINEARITIES AND SIGN-CHANGING POTENTIAL
}

\begin{abstract}
HONG-YING LI
Abstract. In this paper, we study the multiplicity of solutions for a class of concave-convex $p$ Laplacian equations with the combined effect of coefficient functions of concave-convex terms. By the Nehari method and some analysis techniques, we obtain an exact constant for the effect of coefficient functions of concave-convex terms to ensure this problem has two nonzero and nonnegative solutions and give the relation of size of the two solutions. Moreover, under some stronger conditions, we prove that the two solutions are positive. Our results generalize and improve some known results in the literature.
\end{abstract}

Mathematics subject classification (2010): 35A15, 35B09, 35D30, 35J92. method.

Keywords and phrases: $p$-Laplacian equation, concave-convex terms, sign-changing potential, Nehari

\section{REFERENCES}

[1] A. Ambrosetti, H. BréZis And G. Cerami, Combined effects of concave and convex nonlinearities in some elliptic problems, J. Funct. Anal., 122, 2 (1994), 519-543.

[2] H. T. BAnKs, Modeling and Control in the Biomedical Sciences, Lect. Notes Biomath., vol. 6, Springer-Verlag, Berlin, 1975.

[3] L. Boccardo, M. Escobedo and I. Peral, A Dirichlet problem involving critical exponent, Nonlinear Anal. TMA, 24, 11 (1995), 1639-1648.

[4] M. L. M. Carvalho, E. D. Da Silva And C. Goulart, Quasilinear elliptic problems with concave-convex nonlinearities, Commun. Contemp. Math., 19, 6 (2017), 1650050, 25 pp.

[5] D. G. De Figueiredo, J.-P. Gossez ANd P. Ubilla, Local superlinearity and sublinearity for the p-Laplacian, J. Funct. Anal., 257, 3 (2009), 721-752.

[6] J. P. García Azorero, I. Peral Alonso and J. J. Manfredi, Sobolev versus Hölder local minimizers and global multiplicity for some quasilinear elliptic equations, Commun. Contemp. Math., 2, 3 (2000), 385-404.

[7] M. GHERGU AND V. RǍUlescu, Multi-parameter bifurcation and asymptotics for the singular LaneEmden-Fowler equation with a convection term, Proc. Roy. Soc. Edinburgh Sect. A, 135, 1 (2005), $61-83$.

[8] D. Gilbarg and N. S. Trudinger, Elliptic Partial Differential Equations of Second Order, Springer-Verlag, Berlin, 2001.

[9] T. S. HSU, Multiplicity results for $p$-Laplacian with critical nonlinearity of concave-convex type and sign-changing weight functions, Abstr. Appl. Anal., (2009), Art. ID 652109, 24pp.

[10] T. S. HsU, Multiple positive solutions for a class of quasi-linear elliptic equations involving concaveconvex nonlinearities and Hardy terms, Bound. Value Probl., 2011, 37 (2011), 15pp.

[11] T. S. Hsu, Multiple positive solutions for a quasilinear elliptic problem involving critical SobolevHardy exponents and concave-convex nonlinearities, Nonlinear Anal., 74, 12 (2011), 3934-3944.

[12] T. S. HSU AND H. L. Lin, Three positive solutions for semilinear elliptic problems involving concave and convex nonlinearities, Proc. Roy. Soc. Edinburgh Sect. A, 142, 1 (2012), 115-135.

[13] Y. IL'YASOV, On nonlocal existence results for elliptic equations with convex-concave nonlinearities, Nonlinear Anal., 61, 1-2 (2005), 211-236. 
[14] Y. S. ILYASOV, Bifurcation and blow-up results for equations with $p$-Laplacian and convex-concave nonlinearity, Electron. J. Qual. Theory Differ. Equ., 2017, 96 (2017), 13 pp.

[15] H. B. Keller AND D. S. COHEN, Some positone problems suggested by nonlinear heat generation, J. Math. Mech., 16, (1967), 1361-1376.

[16] T. X. Li AND T. F. WU, Multiple positive solutions for a Dirichlet problem involving critical Sobolev exponent, J. Math. Anal. Appl., 369, 1 (2010), 245-257.

[17] F. F. LiAO AND C. L. TANG, Four positive solutions of a quasilinear elliptic equation in $\mathbb{R}^{N}$, Commun. Pure Appl. Anal., 12, 6 (2013), 2577-2600.

[18] J. F. LiAO, Y. PU AND C. L. TANG, Multiplicity of positive solutions for a class of concave-convex elliptic equations with critical growth, Acta Math. Sci. Ser. B (Engl. Ed.), 38, 2 (2018), 497-518.

[19] C. D. LUNING AND W. L. PERRY, Positive solutions of negative exponent generalized Emden-Fowler boundary value problems, SIAM J. Math. Anal., 12, 6 (1981), 874-879.

[20] S. A. Marano And N. S. Papageorgiou, Positive solutions to a Dirichlet problem with $p$ Laplacian and concave-convex nonlinearity depending on a parameter, Commun. Pure Appl. Anal., 12, 2 (2013), 815-829.

[21] A. Nachman and A. Callegari, A nONLinear Singular boundary Value Problem in THE THEORY OF PSEUDOPLASTIC FLUIDS, SIAM J. Appl. Math., 38, 2 (1980), 275-281.

[22] A. PAZY, Semigroups of Linear Operators and Applications to Partial Differential Equations, Appl. Math. Sci., vol. 44, Springer-Verlag, New York, 1983.

[23] W. L. PERry, A monotone iterative technique for solution of pth order $(p<0)$ reaction-diffusion problems in permeable catalysis, J. Comput. Chem., 5, 4 (1984), 353-357.

[24] W. Rudin, Real and complex analysis, McGraw-Hill, New York, London etc., 1966.

[25] K. SILVA AND A. MACEDO, Local minimizers over the Nehari manifold for a class of concave-convex problems with sign changing nonlinearity, J. Differential Equations, 265, 5 (2018), 1894-1921.

[26] M. TANG, Exact multiplicity for semilinear elliptic Dirichlet problems involving concave and convex nonlinearities, Proc. Roy. Soc. Edinburgh Sect. A, 133, 3 (2003), 705-717.

[27] K. M. TENG AND R. P. AGARWAL, Infinitely many solutions for a class of quasilinear equation with a combination of convex and concave terms, Topol. Methods Nonlinear Anal., 50, 1 (2017), 299-332.

[28] N. S. TRUDIngER, On Harnack type inequalities and their application to quasilinear elliptic equations, Comm. Pure Appl. Math., 20, (1967), 721-747.

[29] J. L. VÁZQUEZ, A strong maximum principle for some quasilinear elliptic equations, Appl. Math. Optim., 12, 3 (1984), 191-202.

[30] L. WANG, Q. L. WeI AND D. S. KANG, Multiple positive solutions for p-Laplace elliptic equations involving concave-convex nonlinearities and a Hardy-type term, Nonlinear Anal., 74, 2 (2011), 626638.

[31] T. F. WU, On semilinear elliptic equation involving concave-convex nonlinearities and sign-changing weight function, J. Math. Anal. Appl., 318, 1 (2006), 253-270.

[32] T. F. WU, Three positive solutions for Dirichlet problems involving critical Sobolev exponent and sign-changing weight, J. Differential Equations, 249, 7 (2010), 1549-1578.

[33] L. R. XIA, M. B. YANG AND F. K. ZHAO, Infinitely many solutions to quasilinear elliptic equation with concave and convex terms, Topol. Methods Nonlinear Anal., 44, 2 (2014), 539-553. 